\title{
Experiencing the Shift: How Postsecondary Contract and Continuing Faculty Moved to Online Course Delivery
}

\section{Brock Brock Education}

A journal of educational research and practice

2021 Vol. 30 (2) 63-78

https://journals. library.brocku.ca/brocked

\author{
Patricia Danyluk* and Amy Burns** \\ University of Calgary
}

\begin{abstract}
The shift to online learning that occurred in March of 2020 created an unprecedented period of intense work for faculty and sessional instructors at the postsecondary level. This shift necessitated courses be adapted under short timelines, new technology be integrated into course design, and teaching strategies and assessment methods be adapted for an online environment (Van Nuland et al., 2020). This study examines how sessional instructors, referred to in this article as contract faculty, and continuing full-time faculty members delivering the same online courses experienced this shift. While the demands of a continuing faculty position call for balancing of teaching, research, and service responsibilities, contract instructors have their own unique stressors (Karram Stephenson et al., 2020). Contract faculty lack job security, are paid by the course, and often receive their teaching assignments with short notice. By examining their perspectives on delivering the same courses online, we learn that the shift to online teaching resulted in additional work in order to adapt courses to the online environment, with faculty describing the challenges of balancing the additional work with other responsibilities of their position. Concerns of participants focused on a perceived inability to develop relationships with students in an online environment.

Keywords: continuing faculty, contract faculty, shift to online, pandemic, teaching online

*patricia.danyluk@ucalgary.ca

**amburns@ucalgary.ca
\end{abstract}




\section{Context}

The research reported here was conducted in a university in Western Canada within four undergraduate courses, each originally designed to be conducted face-to-face. Each course was redesigned for the online environment when the need arose due to COVID-19 and, as each consisted of multiple sections taught by a combination of contract faculty and continuing faculty, this redesign was done collaboratively by each instructor group. Table 1 outlines the makeup of each course.

Table 1

Breakdown of Courses Surveyed

\begin{tabular}{cccc}
\hline Course no. & Duration & Size & Faculty involvement \\
\hline 1 & Year $1-$ Fall & 13 sections & -4 contract faculty teaching 5 sections \\
& 10 weeks & 520 students & -5 continuing faculty teaching 8 sections \\
& & & \\
& Year $1-$ Fall & 14 sections & -2 contract faculty teaching 2 sections \\
& 10 weeks & 560 students & -9 continuing faculty teaching 12 sections \\
& Year $2-$ Fall & 14 sections & -8 contract faculty teaching 8 sections \\
& 8 weeks & 560 students & -6 continuing faculty teaching 6 sections \\
& & & \\
& & &
\end{tabular}

Note. Each section of the courses taught by continuing and contract faculty had an average of 40 students per course. The courses are standard 39-hour, half-credit courses and are a mandatory part of the degree.

The Faculty in which these courses were taught is one with a relatively long history of online course offerings, meaning that some but not all course instructors would have experience with online education. This experience would be more likely if those teaching also were involved with the delivery of courses at the graduate level, as online delivery was less common at the undergraduate level in which these courses were offered.

When the shift to online learning first occurred in March 2020, all faculty members were supported through a series of online workshops designed to enhance online teaching within the Faculty. These weekly workshops included information and hands-on practice with issues such as using synchronous technology, online assessment practices, and promoting engagement in online environments. Although both continuing and permanent faculty had access to the 
sessions, attendance was optional. As each course had several sections and therefore several faculty teaching the course, the common practice was to create a community of practice (Wenger et al., 2002) whereby instructors would meet monthly or in some cases weekly to share approaches, lesson plans, and resources. Each faculty member also had support in the form of one-on-one technology coaching, available upon request. At the university level, faculty could access multi-day workshops that explored online teaching in more depth.

Another important element of the research reported here is the distinction between contract faculty and continuing faculty within the institution where the research took place. While on contract to teach, the contract faculty at the institution reported here are members of the teaching association and are afforded many of the same considerations of continuing, full-time faculty members. Examples of supports open to all contract and continuing faculty include a professional expense fund that is determined based on the number of courses taught as well as access to mental health supports such as counseling; however, these affordances do not extend beyond the length of the contract. Additionally, many of the contract faculty in this study were long-standing retired teachers and principals and had taught various times over several years, often teaching more than one course per semester. Finally, the contract faculty noted here do not hold the requirement for service or research as theirs is purely a teaching role, although many contract faculty have chosen to participate in committees or research teams in the past.

\section{Literature Review}

Over the last decade there has been a shift towards the use of contract or sessional labour at universities not only in Canada but also in the United States, the United Kingdom, and Australia (Field et al., 2014; Muzzin, 2009). In 2018, the Canadian Union of Public Employees reported that $54 \%$ of faculty appointments in Canada were short-term, contract, part-time casual, or temporary. The increasing number of sessional or contract faculty in Canadian universities has been linked to decreased funding for universities (MacDonald, 2013; Rose, 2020). While enrollment in Canadian universities has steadily increased, the number of tenure track faculty positions has not kept pace (Canadian Association of University Teachers [CAUT], 2013; Field et al., 2014; Karram Stephenson et al., 2020). While the role of sessional faculty is to focus solely on teaching, tenure track or tenured faculty must balance responsibilities for teaching, research, and service (Karram Stephenson et al., 2020). Higher percentages of contract faculty are found in social science and humanities fields where they are more likely to teach labourintensive undergraduate courses (Gopaul et al., 2016; Rose, 2020).

Contract faculty are often hired on a course-to-course basis and hold little or no job security (Field \& Jones, 2016). In some institutions, contract faculty are eligible for benefits such as health plans, pensions, and leaves of absence under collective agreements (Field \& Jones, 2016). They do not, however, have the same level of job security as those in a full-time 
academic position. Field and Jones (2016) identified two categories of contract faculty: Classic contract faculty are current or retired professionals who teach to share their knowledge or to enhance their income; precarious contract faculty are those who rely on the income from their sessional teaching and aspire to a full-time academic position. While precarious contract faculty are more likely to be female and hold a PhD, classic contract faculty are more likely to be male and not hold a PhD (Field \& Jones, 2016; Field et al., 2014).

Canadian academics report an intensification of their work with increased pressures to secure external funding (Gopaul et al., 2016) and produce high-profile research (Wilton \& Ross, 2017). Descriptors such as competitive (Davies, 2016) and cutthroat (Wilton \& Ross, 2017) have been used to describe the current academic culture. Among the stressors for full-time faculty are pressures associated with achieving tenure, publishing, increased class sizes, and adapting to new technologies (Pomerance, 2008). Canadian academics report working an average of 50.7 hours per week when teaching and 47.7 hours when not teaching (Gopaul et al., 2016). Achieving work-life balance is a constant struggle, with women academics reporting higher levels of difficulty resulting from additional responsibilities at home (Wilton \& Ross, 2017). While full-time faculty report enjoying both teaching and research, they show a slight preference for research over teaching (Karram Stephenson et al., 2020). The majority of faculty in Canada (94.6\%) teach in a classroom or lecture setting (Karram Stephenson et al., 2020). As of 2018 , only $17.8 \%$ of full-time professors reported teaching in a computer-assisted learning environment (Karram Stephenson et al., 2020).

Permanent faculty have the advantage of having better access to support and training for course adaptation to online than contract faculty (Merillat \& Scheibmeir, 2016). However, several studies have reported that faculty are reluctant to teach online, viewing it as inferior and as more work than face-to-face teaching (Allen \& Seaman, 2010; Chiasson et al., 2015; Panda \& Mishra, 2007) with undergraduate faculty demonstrating the greatest resistance to online teaching (Allen \& Seaman, 2010). Faculty with more computer experience demonstrate greater acceptance of online teaching (Panda \& Mishra, 2007) with positive attitudes towards online teaching increasing steadily (Allen \& Seaman, 2010). Faculty with little or no online teaching experience have limited views regarding the types of teaching activities available to them when teaching online. In their examination of perceptions of online teaching Fish and Gill (2009) found that faculty with little or no experience with online teaching believed that suitable teaching strategies for online learning were limited to lecture, case studies, and research. Faculty with more experience teaching online expanded upon those teaching strategies to include group discussions and group work (Fish \& Gill, 2009).

Learning how to teach online requires much more than just an understanding of the technology involved (Jackson \& Jones, 2019). A positive attitude towards the technology, ability to use the 
technology, and an interactive teaching style enhance the perceived efficacy of the learning for students (Webster \& Hackley, 1997). Students in online courses describe experiencing a sense of community in the course as being connected to positive perceptions of the course Jackson $\&$ Jones, 2019). Student engagement is enhanced by activities such as icebreakers, collaborative work, peer presentations, and peer review of assignments (Bolliger \& Martin, 2018). Teaching online requires a shift in the cognitive, management, and affective roles of the facilitator (Coppola et al., 2002). In a study of changes that occur when faculty shift to online teaching, Coppola et al. (2002) found that in addition to involving deeper cognitive complexity, online teaching demanded more attention to managerial functions such as attention to detail, as well as consideration of the affective dimension of learning which includes new ways to express emotion in the online learning environment. The most successful online teachers are those who not only understand the technology but also enjoy using it (DiPietro et al., 2008). In their examination of award-winning faculty online teaching practices, Martin et al. (2019) found that such faculty consider learner needs and interaction in their course design, use a variety of assessment strategies, and provide timely responses and feedback to students.

The shift to online learning in March 2020 resulted in additional work for those teaching online. New technologies requiring professional development were introduced through online webinars designed to support online teaching (Van Nuland et al., 2020). The degree of the challenge for teacher educators shifting to online learning depended on how familiar they were with online teaching. For those who had previous experience teaching online, the challenge was not as great as for those who had never delivered an online course (Van Nuland et al., 2020). For contract faculty, full-time faculty, and students who had older computers, this necessitated upgrading to computers that had audio and video capabilities (Van Nuland et al., 2020). Contributing to the complexity of the shift to online learning was a growing awareness that additional attention needed to be placed on student wellness during this period (Burns et al., 2020; Hill et al., 2020). The isolation resulting from the shift to online learning impacted productivity, creativity, and mental well-being of students and faculty members alike (Goedegebuure \& Meek, 2021). Working, learning, and caregiving from home made finding quiet, uninterrupted space a rarity, further enhancing the inequities experienced amongst faculty members (Metcalfe, 2021).

\section{Methodology}

This study draws upon a scholarship of teaching and learning (SoTL) framework as the study sought to better understand how contract and full-time faculty experienced the shift to online learning and how they could be best supported in their online teaching. The purpose of engaging in SoTL is to improve student learning and educational quality (Poole $\&$ Simmons, 2013). In an examination of the challenges of SoTL, McKinney (2009) defines "SoTL as 
systematic reflection and study on teaching and learning made public" (p. 38). By engaging in research about teaching, the scholarship of teaching and learning acts as a bridge between the research and teaching (Hutchings et al., 2013).

This research study was designed using a case study methodology (Stake, 2006), whereby four courses taught in the fall session of 2020 at a university in Western Canada were considered a case. The case study employed allowed for an in-depth examination of the four courses and was bound by three factors. First, each of the courses was originally designed to be taught in a face-to-face format and was required to be retooled for the online environment. Second, each course was taught by a mixture of both continuing and contract faculty. Finally, each course was offered between September and December 2020.

The four courses chosen for this case study were delivered at the undergraduate level of a postsecondary professional program. Each of the courses consisted of multiple sections, each following the same course outline with consistent assignments, rubrics, and number of scheduled synchronous sessions. As per the standard set within the undergraduate Faculty under investigation, each of the four courses had four synchronous sessions per section and a total of three assignments, making the number of contact hours and workload expectations very similar across the groups. Additionally, all contract faculty and continuing faculty delivering the courses had the freedom to add additional resources and synchronous sessions to their delivery of the course as they believed appropriate.

After institutional ethics were received, data were gathered through an online survey using Qualtrics, document analysis of the four course outlines, and a review of the literature. Using Qualtrics ensured that all responses were anonymous and could not be linked to a specific participant, although participants were asked if they were contract or continuing faculty to ensure comparisons could be made. The invitation to participate in the survey was sent out by the program office. The survey link was sent to the 20 contract faculty and 28 continuing faculty responsible for course delivery of the four courses during the fall session. A total of 20 responses were received, representing a $41 \%$ participation rate.

\section{Limitations}

As the majority of the responses were from sessional or contract instructors and only four (or $20 \%$ ) of the responses received were from continuing faculty, the findings should be read in light of the unequal distribution. As a result, it difficult to compare and contrast responses except in a generalized manner.

\section{Data Analysis}

The survey responses were analyzed by the researchers to determine consistent themes through the responses as well as comparisons between contract and continuing faculty 
responses. Survey data were both numerical, using a Likert-type scale and text-based. To ensure an accurate description of participant experiences, all text-based data were coded and included in the percentages provided by the numerical data. Given the types of questions asked in the survey instrument, although a number of questions asked for numerical responses, all data were treated as qualitative insofar as no statistical methods were applied outside of determining the mean. The four course outlines associated with each course were also analyzed thematically. In each, commonalities and differences in the manner in which the online environment was addressed were noted and were found to highlight various ways in which faculty addressed the change in the teaching modality from face-to-face to online.

\section{Results}

From the survey data, course outlines, and literature, the researchers identified four consistent themes: the challenges of teaching online, the perception of an inability to develop relationships with students, adaptations to courses by instructors, and the advantages of teaching online.

Fifty percent of the respondents described the shift to online learning as being moderately challenging, citing issues such as course redesign and modifications to pedagogical practice as creating additional work. One respondent described the process of shifting a face-to-face course to online as requiring a "huge investment of time" while another described "increased preparation time." Fifty percent of respondents described having taught online before or having completed a portion of their graduate studies online, making them familiar with the technical aspects of online teaching. In their response, 63\% described concern about building relationships with students in an online environment. Respondents described building relationships with students in an online environment as more challenging than in a face-to-face course, with one indicating "I believe the key to teaching is establishing honest strong relationships with my students. It is difficult to develop these relationships in an online environment" and another indicating that they found it "more difficult to develop relationships and model teaching strategies beyond the ones that are suited to an online environment."

\section{Challenges of Teaching Online}

Participants described the shift to online teaching as being more time consuming than face-to face in the classroom teaching. Fifty-seven percent of the responses from contract faculty indicated they found teaching online to be more work. From the continuing faculty responses, $50 \%$ described teaching online as being more time consuming. In an attempt to build relationships with students, respondents increased efforts to connect through written contact in the form of email and written descriptions of expectations, with one sessional instructor stating, "I found that I needed to be in contact with my students more often and it was tough to know if I was connecting. Also, there was a great amount of 'written' explanation that was 
required that would of course been easier in a face-to-face class." Consistently, a faculty member identified online teaching as more work and described the need to stay connected with students as time intensive: "I try to be super accessible and responsive to students, but without regular in-person classes my email volume has quadrupled. Additionally, the online discussion is time intensive-valuable and meaningful-but just takes more time." This challenge of increased time taken to facilitate student discussion in the online environment was supported by the analysis of the course outlines. Each of the four courses examined required students to provide some form of written discussion, be it in the form of blogs or discussion posts, either in large or small groups. This reliance on written discussion appeared within the course outlines to replace the in-person conversation that would normally occur in a face-to-face course and would both add to the richness of the online environment but also impact the workload significantly for faculty attempting to engage in all of the conversations happening in text form.

Contract faculty were much more likely to indicate they had added additional synchronous sessions to the course, with $67 \%$ of the contract faculty indicating they had added an additional synchronous session and none of the continuing faculty respondents indicating they had done so. Those who indicated they had added additional synchronous sessions to their course did so because they felt students would benefit from the increased connection with their classmates and their instructor. One instructor noted, "students have so many questions, and also are hungry for connection with both each other and the Instructor," with another stating they offered weekly synchronous sessions, more than three times the number in other course sections. The latter participant indicated, "I offered weekly optional Zoom sessions in order to support students with their ongoing assignments, and to discuss any of their concerns or suggestions. I also offered to Zoom meet with my students during any other scheduled group work time or if they had individual questions." Two contract faculty described using synchronous sessions to reduce issues of inequity by providing additional support for students who were struggling: "The best part of teaching online is that I can meet privately with students in Zoom when they need extra help" and another suggested,

I connect with my students with diverse learning needs more frequently because I have the time. They are not singled out in an online class because we can meet privately. The confidentiality of learning needs of each students is important and it is very easy to have a quick Zoom session in private to address their learning difficulties and help them one on one.

Along with the additional synchronous sessions, respondents described adding additional breakout sessions for students to discuss course content or to work on a group project, as well as additional virtual office time for students to ask questions about assignments. Eighty-three percent of contract faculty responses indicated they had added additional resources such as articles, links to resources, new items, and Google documents. Only $50 \%$ of continuing faculty 
indicated they had added supplemental resources to the course. Several respondents referred to creating videos in which they described an upcoming assignment or provided a lecture on course content. Those who did not add additional resources to their course indicated that they decided not to do so out of concern for student workload. One respondent indicated that they had "removed some of the readings and revised discussion times to be less in this pandemic environment because students are over-Zoomed and experiencing screen fatigue."

Continuing faculty respondents were more likely to indicate that they found it more challenging to balance online teaching with research, writing, and committee and grant work. Sixty-seven percent of full-time faculty described it as more difficult, while none of the contract faculty indicated that they did. Interestingly, one contract faculty member indicated "I would like to be more involved in research and committee work, but this does seem to be an option as a sessional instructor."

Faculty members described devoting additional time to online communication and student wellbeing, leaving less time for other responsibilities. Having to adapt planned research to online environments was described by faculty as making the task of balancing responsibilities more challenging.

\section{Developing Relationships With Students}

Respondents described the most negative aspect of teaching online as being the inability to connect with students, referring to feelings of being "disconnected" or "out of touch" and frustrated over the inability to get to know students and connect with them through a class discussion or an individual conversation. The feeling of disconnection extended to time spent in synchronous sessions, with one respondent indicating there was a "lack of feedback from students during Zoom sessions" and another stating, "I catch myself talking to a computer not knowing if anyone is listening or understanding." Others described the inability to see body language and facial expressions as a disadvantage that contributed to a sense of frustration with the inability to read the room and adapt accordingly. For some contract faculty, being around students was their impetus for teaching, with one respondent expressing a sense of loss resulting from the isolation: "Not being with the people in the room. I REALLY miss that. I don't HAVE to teach so I'm doing this because I want to." Similarly, another contract faculty expressed disappointment about "Not being able to share lived experience with my students, and them not benefitting from that kind of community."

Interestingly, each of the course outlines analyzed in this study continued to discuss the importance of the learning community and noted the expectation of students to engage meaningfully in discussion and inquiry. This was likely due to standard language required of course outlines to describe the importance of class participation but notably this language still 
held true in the online environment as evidenced by the assignments presented in each course. All four courses still required students to complete group tasks and to engage in learning communities of various sizes and configurations.

The need to remain a part of a vibrant learning community, however, did not negate the concern many faculty had for student well-being. As each of the courses was delivered during the pandemic, several respondents described concern for student mental health during the time of social isolation, with one indicating frustration over the inability to recognize that not all students have equal access to supports:

Student fatigue, declining mental health and well-being of students and instructors, and the fact that course expectations remain the same and not being really responsive to students' needs and many personal challenges (e.g., social isolation, smaller support networks, disconnection from family and friends, home schooling, loss of income, living conditions that don't accommodate online work, etc.).

\section{Advantages of Teaching Online}

Respondents also described the positive aspects of teaching online as offering freedom and flexibility for both faculty and students. Fifty percent of the respondents described appreciating online teaching because of flexible timelines. Twelve percent of respondents indicated that the opportunity to teach online made them feel safer than they would have if they were teaching face-to-face during the pandemic. Twenty-five percent of respondents indicated they appreciated online teaching as it meant they did not need to commute to the workplace. Twenty-five percent of the respondents indicated they recognized the potential of online teaching, describing it as "wide open for growth" and an opportunity to "explore new methods of teaching and learning." Another respondent envisioned the potential of online teaching and learning for collaborations, "locally, regionally, nationally, and internationally." In what follows, these findings are further explored.

\section{Discussion}

From the results of this study, it is clear that both contract faculty as well as continuing faculty who shifted their courses from face-to-face delivery to online found the shift moderately challenging, necessitating additional time-intensive work. While $57 \%$ of contract faculty indicated the shift was more work, only $50 \%$ of continuing faculty did. This difference may be related to varying levels of experience with online teaching. While the majority of continuing faculty within this program have experience teaching online, the contract faculty may have had less experience teaching online, which may account for the difference (Panda \& Mishra, 2007). Many of the continuing undergraduate faculty were required to learn how to teach online during the previous 5 years when a blended delivery program was added in order to meet the needs of 
students living at a considerable distance from the university. Consistent with Allen and Seaman (2010), Chiasson et al. (2015), and Panda and Mishra (2007), there is a contingent of faculty who prefer to teach face-to-face, viewing the online experience as being of a lesser quality and requiring more preparation time.

Among the greatest challenges reported was that of building relationships with students in an online environment. Several respondents indicated they had felt disconnected from their students and that they had been unable to create a relationship of trust. Contributing to the sense of being disconnected was frustration over a lack of student feedback during the synchronous sessions due to the inability to see student reactions. Synchronous sessions can be used for a multitude of purposes but perhaps one of the more important is creating a sense of community in the classroom (Jackson \& Jones, 2019). This can be accomplished through interactive activities such as icebreakers and collaborative activities such as peer presentations and peer review (Bolliger \& Martin, 2018). This, however, leaves less time for the instructor to convey content through lecture. Alternative solutions may reside in creating videos or podcasts wherein course content is communicated to students, leaving synchronous sessions for relationship building, clarifications, and questions about the content.

One of the more interesting findings of the study was that $67 \%$ of the contract faculty added additional synchronous sessions to the course while none of the continuing faculty did. One of the contract faculty described tripling the number of synchronous sessions in order to support students. While each of the courses were designed with four synchronous sessions, some of the responses indicated that students appreciated additional sessions because they were experiencing the effects of isolation due to the pandemic. What is the ideal number of synchronous sessions for a 10-week course? Where is the line between providing support for students through additional synchronous sessions and contributing to online fatigue and feelings of being overwhelmed resulting from the additional sessions? This balance becomes more challenging when one considers that students are simultaneously taking five courses during which they are also meeting to complete group tasks, thereby increasing their time spent online. As continuing faculty were more likely to be teaching several online courses during the time, they may have had additional insight into the work levels of students in other courses and may have been reluctant to contribute to that by adding additional synchronous sessions. Another contributing factor to continuing faculty not adding additional synchronous sessions may be the additional stressors they were experiencing at the time, including pressure to publish and complete service responsibilities, making them less likely to want to increase their own workload by additional synchronous sessions (Pomerance, 2008).

The majority of the contract faculty who responded to the survey would be described as classic contract as opposed to the precarious contract (Field \& Jones, 2016) as the Faculty in which this 
research took place employs only a small number of precarious contract faculty. While continuing faculty would have been responsible for teaching several courses at a time, contract faculty would likely be teaching only one or two at a time. This context may provide additional insight into the reasons why additional synchronous sessions were more likely to be added by contract faculty. Classic contract faculty teach because they enjoy sharing their knowledge and spending time with students (Field \& Jones, 2016). In addition, many classic contract faculty are made up of retired professionals who teach because they want to experience a sense of community found in a face-to-face teaching; online teaching may not have met that need. Adding to the lack of community is the likelihood that contract faculty may themselves struggle with a sense of isolation and adding additional synchronous sessions may have helped to alleviate that. It is also likely that classic contract faculty experiences with communities of learning and online teaching in schools prior to teaching at the university may have led them to expect more frequent student interaction. In light of our growing awareness of the experiences of isolation and loneliness experienced by faculty and students during the pandemic (Goedegebuure \& Meek, 2021), increased online engagement may be a welcome antidote for some and an additional burden for others. Interestingly, two contract faculty described adding individual synchronous sessions as a way of supporting struggling students or students experiencing learning difficulties. The confidentiality of such sessions means that the student would not be singled out in front of the class, making the online environment a more equitable one for students who require individualized one-on-one support.

While both contract faculty and continuing faculty added resources to the course, contract faculty were more likely to do so. As continuing faculty were more likely to have designed the course, it is possible that they saw the course as being significantly robust so as to not necessitate additional resources. Additional resources that were added included articles, links to resources, new items, and Google documents. It appears that Google documents were used for group work but also provide the additional benefit of allowing the instructor to offer formative feedback to assignments in progress.

One contract faculty member indicated that they would like to be invited to participate on committees and research teams even though it was not an expectation of their role and it is possible that others share in this desire. Continuing faculty may be reluctant to invite contract faculty to take on additional responsibilities outside of their role when in fact, contract faculty may welcome the opportunity. The danger in doing so lies in how the invitation is perceived by the contract faculty member. Any such invitation would need to explicitly indicate that such participation is not an expectation of contract faculty.

The pandemic brought an intensive period of work for contract as well as continuing faculty (Goedegebuure \& Meek, 2021). The results of this study make it clear that the perceived 
advantages to online teaching were experienced by both contract faculty and continuing faculty in a similar way, although contract faculty added more frequent student interaction to their courses. Responses described a new sense of freedom and insight into the potential of online learning. In addition, respondents expressed a new appreciation for the flexibility of being able to work from home. While students may have appreciated additional contact provided by contract faculty through additional synchronous sessions, questions remain about when too much support via synchronous sessions contributed to a feeling of being overwhelmed, Zoomed-out, or fatigued by the workload. Through professional development on teaching strategies suitable for online teaching, we can contribute to the efficacy of online learning for students as well as enhance faculty perceptions of online teaching.

\section{Conclusion}

As academics, we require personal interaction to do our best work. Nothing can replace the informal discussions with colleagues that not only combat social isolation but also spark creativity (Metcalfe, 2021). From this study we can conclude that issues around creating a sense of community in the classroom are one of the more significant challenges experienced by faculty. While synchronous sessions can be used for activities that contribute to relationship building, doing so leaves less time for faculty to convey course content. By providing technical support for faculty to convey course content through videos or podcasts, the limited time available for synchronous sessions may be focused on creating supportive relationships with students.

The pandemic has increased our awareness of issues of inequity in our society. These inequities extend to the differences between benefits and responsibilities of contract faculty and continuing faculty. Yet these inequities are put aside in the context of our care and concern for student wellness. While most contract faculty increased the amount of synchronous sessions provided to students, they were careful to make sessions one-on-one or optional. Adding additional synchronous sessions resulted in additional work for the contract faculty. At the same time, many continuing faculty chose not to increase the number of synchronous sessions, fearing that students may perceive extra sessions as an additional burden. Perhaps, the question of whether to add additional synchronous sessions requires student input. The pandemic has thrust us into online learning, with limited opportunities to ask students what works best for them.

While the pedagogy of teaching online continues to evolve, there is a need for professional development to expand both contract and continuing faculty's repertoire of teaching strategies suitable for online learning. The researchers plan to examine powerful teaching strategies in online environments as a next step. 


\section{References}

Allen, I. E., \& Seaman, J. (2010, January). Learning on demand: Online education in the United States, 2009. Babson Survey Research Group. https:/ / files.eric.ed.gov/fulltext/ED529931.pdf

Bolliger, D. U., \& Martin, F. (2018). Instructor and student perceptions of online student engagement strategies. Distance Education, 39(4), 568-583. https://doi.org/10.1080/01587919.2018.1520041

Burns, A., Danyluk, P., Kapoyannis, T., \& Kendrick, A. (2020). Leading the pandemic practicum. One teacher education response to the COVID-19 crisis. International Journal of ELearning and Distance Education, 35(2). http://www.ijede.ca/index.php/jde/article/view/1173

Canadian Association of University Teachers. (2013). CAUT almanac of post-secondary education, 2012-2013. https://www.caut.ca/docs/almanac/2012-2013-caut-almanacof-post-secondary-education-in-canada.pdf?sfvrsn $=0$

Chiasson, K., Terras, K., \& Smart, K. (2015). Perceptions of moving a face-to face course to online instruction. Journal of College Teaching \& Learning, 12(3), 231-240. https://doi.org/10.19030/tlc.v12i3.9315

Coppola, N. W., Hiltz, S. R., \& Rotter, N. (2002). Becoming a virtual professor: Pedagogical roles and ALN. Journal of Management Information Systems, 18(4), 169-190. https:/ / doi.org/10.1080/07421222.2002.11045703

Davies, W. (2016). The limits of neoliberalism: Authority, sovereignty and the logic of competition. SAGE.

DiPietro, M., Ferdig, R. E., Black, E. W., \& Preston, M. (2008). Best practices in teaching K-12 online: Lessons learned from Michigan Virtual School teachers. Journal of Interactive Online Learning, 7(10), 10-35. http://iols.gmu.edu/assets/761 / Article2e.pdf

Field, C. C., \& Jones, G. A. (2016). A survey of sessional faculty in Ontario publicly-funded universities. Centre for the Study of Canadian and International Higher Education, OISEUniversity of Toronto. https://ciheblog.files.wordpress.com/2016/08/full-report.pdf

Field, C. C., Jones, G. A., Karram Stephenson, G., \& Khoyetsyan, A. (2014). The "other" university teachers: Non-full-time instructors at Ontario universities. Higher Education Quality Council of Ontario. https://heqco.ca/wp-content/uploads/2020/03/Non-full-time-instructorsENG.pdf

Fish, W. W., \& Gill P. B. (2009). Perceptions of online instruction. The Turkish Online Journal of Educational Technology, 8(1), Article 6. https://eric.ed.gov/?id=ED503903

Goedegebuure. L., \& Meek, L. (2021). Crisis-What crisis? Studies in Higher Education, 46(1), 14. https://doi.org/10.1080/03075079.2020.1859680 
Gopaul, B., Jones, G. A., Weinrib, J., Metcalfe, A., Fisher, D., Gingras, Y., \& Rubenson, K. (2016). The academic profession in Canada: Perceptions of Canadian university faculty about research and teaching. Canadian Journal of Higher Education, 46(2), 55-77. https://doi.org/10.47678/cjhe.v46i2.185269

Hill, C., Rosehart, P., St. Helene, J., \& Sadhra, S. (2020). What kind of educator does the world need today? Reimagining teacher education in post-pandemic Canada. Journal of Education for Teaching, 46(4), 565-575. https://doi.org/10.1080/02607476.2020.1797439

Hutchings, P., Borin, P., Keesing-Styles, L., Martin, L., Michael, R., Scharff, L., Simkins, S., \& Ismail, A. (2013). The scholarship of teaching and learning in an age of accountability: Building bridges. Teaching \& Learning Inquiry, 1(2), 35-47. https:/ / doi.org/10.20343/teachlearninqu.1.2.35

Jackson, B. L., \& Jones, W. M. (2019). Where the rubber meets the road: Exploring the perceptions of in-service teachers in a virtual field experience. Journal of Research on Technology in Education, 51(1), 7-26. https://doi.org/10.1080/15391523.2018.1530622

Karram Stephenson, G., Jones, G. A., Bégin-Caouette, O., \& Metcalfe, A. S. (2020). Teaching, research and the Canadian professoriate: Findings from the 2018 APIKS survey. Higher Education Forum, 17, 25-41. https://doi.org/10.15027/48953

MacDonald, M. (2013, January 9). Sessionals, up close. University Affairs. https://www.universityaffairs.ca/features/feature-article/sessionals-up-close/

Martin, F., Ritzhaupt, A., Kumar, S., \& Budhrani, K. (2019). Award-winning faculty online teaching practices: Course design, assessment and evaluation, and facilitation. The Internet and Higher Education, 42, 34-43. https://doi.org/10.1016/j.iheduc.2019.04.001

McKinney, K. (2006). Attitudinal and structural factors contributing to challenges in the work of the scholarship of teaching and learning. New Directions for Institutional Research, 2006(129), 37-50. https://doi.org/10.1002/ir.170

Merillat, L., \& Scheibmeir, M. (2016). Developing a quality improvement process to optimize faculty success. Online Learning, 20(3), 159-172. https://doi.org/10.24059/olj.v20i3.977

Metcalfe, A. S. (2021). Visualizing the COVID-19 pandemic response in Canadian higher education: An extended photo essay. Studies in Higher Education, 46(1), 5-18. https:/ / doi.org/10.1080/03075079.2020.1843151

Muzzin, L. (2009, May). Equity, ethics, academic freedom and the employment of contingent faculty. Academic Matters, 19-22.

https://academicmatters.ca/assets/Academic_May09_web.pdf 
Panda, S., \& Mishra, S. (2007). E-Learing in a mega open university: Faculty attitude, barriers and motivators. Educational Media International, 44(4), 328-338.

https://doi.org/10.1080/09523980701680854

Pomerance, S. (2008, March 10). The stress of academe. University Affairs. https://www.universityaffairs.ca/news/news-article/the-stress-of-academe/

Poole, G., \& Simmons, N. (2013). The contributions of the scholarship of teaching and learning to quality enhancement in Canada. In G. Gordon \& R. Land (Eds.), Quality enhancement in higher education: International perspectives (pp. 118-128). Routledge. https:/ / doi.org/ 10.4324/9780203590218

Rose, D. (2020). A snapshot of precarious academic work in Canada. Journal of Marxism and Interdisciplinary Inquiry, $17(1), 7-17$. https://ojs.library.ubc.ca/index.php/newproposals/article/view/192381

Stake, R. E. (2006) Multiple case study analysis. The Guilford Press.

Van Nuland, S., Mandzuk, D., Tucker Petrick. K., \& Cooper. T. (2020). COVID-19 and its effects on teacher education in Ontario: A complex adaptive systems perspective. Journal of Education for Teaching, 89(4), 547-561. https:/ / doi.org/10.1080/02607476.2020.1803050

Webster, J., \& Hackley, P. (1997). Teaching effectiveness in technology-mediated distance learning. Academy of Management Journal, 40(6), 1282-1309. https:/ / doi.org/10.2307/257034

Wenger, E., McDermott, R., \& Snyder, W. M. (2002). Cultivating communities of practice: A guide to managing knowledge. Harvard Business School Press.

Wilton, S., \& Ross, L. (2017). Flexibility, sacrifice and insecurity: A Canadian study assessing the challenges of balancing work and family in academia. Journal of Feminist Family Therapy, 29(1-2), 66-87. https://doi.org/10.1080/08952833.2016.1272663 